\title{
CHEMILUMINESCENCE OF LIQUID POOL FLAME WITH NICKEL CHLORIDE AND COPPER SULPHATE
}

\author{
Mayur Anvekar \\ Department of Aeronautical Engineering \\ KLS, GIT, Belagavi, Karnataka, India
}

\author{
Venkatesh Kusnur \\ Department of Aeronautical Engineering \\ KLS, GIT, Belagavi, Karnataka, India
}

\begin{abstract}
The pool flame is a diffusion flame which stands on top of an evaporating volatile fuel. The vapors of the fuel mix with the ambient air results in a combustible fueloxidizer mixture which helps the flame to stand on the pool. The species involved in the combustion process have movement at certain rates which is difficult to observe and quantify. In this research work, an attempt is made to bring a new method to quantify the flow field of the diffusion pool flame by tracking the species. Few salts which easily dissolve in fuel and does not involve in the thermochemical process are used in the research work and the chemiluminescence of the salt in the flame is tracked and correlated with the outer flow field of the flame using Shadowgraph results. The chemiluminescence due to nickel chloride and copper sulfate in pool flame describes the dynamics of combustion species.
\end{abstract}

Keywords- Pool flame, chemiluminescence, vortex shedding, shadowgraph, alcohols.

\section{INTRODUCTION}

Liquid pool diffusion flame is a non-premixed flame on top of an evaporating liquid pool. The fuel evaporates from the pool due to its volatile nature and diffuses in ambient creating a zone for combustion. As the diffusion flame is very much different from premixed type, the diffusion flame is characterized using flame height and not by flame velocity.

In Pool flame, it is commonly excepted that the larger the fuel supply rate, the larger the heat release rate, and the larger the flame height [1]. When the mass burning rate of a flame exceeds a certain value, the flow field ceases to be laminar. As the mass burning rate continues to increase, the flow field changes from buoyancy controlled to momentum dominated [1].The pool flame anchoring is governed by the alcohol mixing with air and the flame governs the combustible gas production. So, a long steady flame means obtaining steady heat exchanges between the flame and the liquid in order to feed the flame with a constant combustible fuel flow rate [2]. Pool flames are expected to be shorter in height and duration and larger in effective diameter. Large diameters also imply poor entrainment, therefore enhanced soot production in higher hydrocarbon pool flames [6]. Based on the Froude number and Grashof number which are determined using the pool flame diameter, the pool flame is categorized as laminar or turbulent, and buoyancy or momentum controlled flame.

A diffusion flame is heterogeneous flame in which the fuel vapors rise from the pool pan and diffuses into ambient air creating a reaction zone in a particular path. The flame initially spread over the pool on ignition and creates almost steady rate of fuel evaporation. The initial spread is transient, later the burning rate becomes steady. Laser induced velocity measurement techniques are widely used in determining the flow field of a small pool flame by tracking the particles in the flame zone [8]. The techniques include forceful entrainment of external seeding particles which will change the physical structure of flame and the burning behavior as well.

The flow field or species movement path is very difficult to track because, the fuel evaporation rate is less and tracking particles are difficult to seed inside the flame without disturbing the flame which has natural diffusion of reactants, hence it is not possible to find the reactant flow field with conventional non-intrusive methods. Using one of the flow visualization technique shadowgraph, it is possible to visualize the flame vortices shedding around the flame which explains part of the air entrainment physics and flame tip puffing. The relatively cool ambient air approaches the pool flame and gradually gets heated due to radiation and convection. Near the flame periphery air participates in creating a combustible mixture which is further carried above by the fuel evaporating from the pool and also due to the buoyancy. The diffusing ambient air near the flame creates vortices due to density gradient which rises along with the species involved in the combustion process. Along the flame height from the pool rim, the fuel concentration depletes by producing heat and light energy whereas the air entrainment continues which further results in flame pinch-off neat the tip of the flame. The vortices also results in continuous flame tip puffing at certain frequency.

\section{METHODOLOGY}

In this research paper, a pool of size $0.05 \mathrm{~m}$ in diameter and $0.025 \mathrm{~m}$ in pool depth is used. As shown in 
figure 1. The fuel level in the pool is maintained up to the brim by continuous external fuel feeder and reservoir arrangement considering its burn rate and ullage. A transparent closed enclosure is used to resist the ambient air disturbance and also to capture the high speed images of pool flame. For the pool diameter, the flame is found to be laminar and buoyancy controlled based on Froude number and Grashof number. Methanol and Ethanol fuels are used which doesn't produce soot as product. Calculated amount of specific chemical crystals are dissolved completely in these fuels before combustion. It is also observed that the salt does not participate in the thermo chemical reaction at ambient conditions. Once this mixture is ignited in the pool, a flame is established on top of the liquid pool and the dissolved salt starts dissociating into the flame as small fragments.

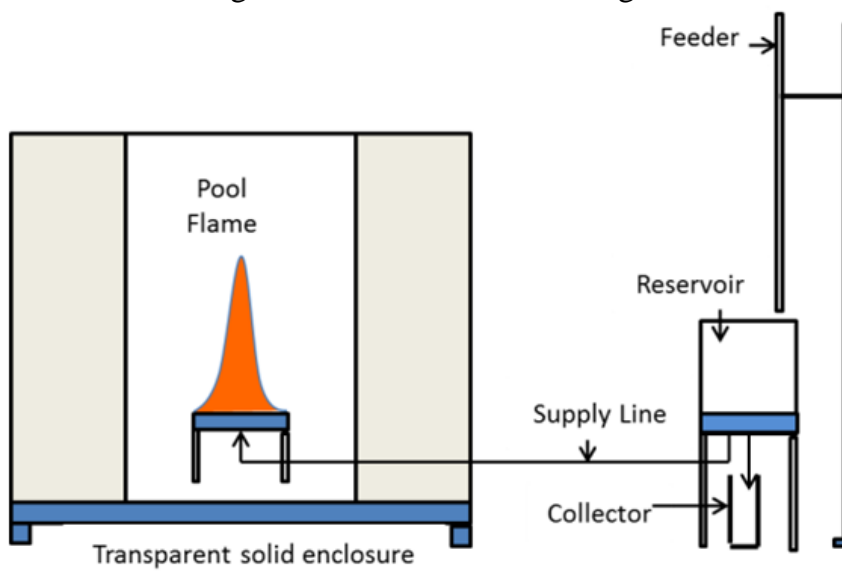

Fig. 1. Pool Flame setup

The dissociated salt inside the flame reaction zone consumes some amount of heat energy and starts illuminating light or chemiluminescence. Copper sulfate $\left(\mathrm{CuSO}_{4}\right)$ and nickel chloride $\left(\mathrm{NiCl}_{2}\right)$ are the two chemical salts used in methanol and ethanol fuels. These dissolved salts are found to remain in stable state in ambient conditions. The Stoichiometric chemical equation for methanol diffusion flame is shown in equation one in which one mole of methanol need 1.5 moles of air to have complete combustion producing one mole of carbon dioxide and two moles of nitrogen and water vapors each. In equation 2 and 3 represents the chemical reaction of methanol and air with copper sulfate and nickel chloride salts in it where the salts doesn't react with other species involved in the combustion. Similarly for ethanol fuel the reactions are shown in equation $4 \& 5$.

$$
\begin{aligned}
& \mathrm{CH}_{3} \mathrm{OH}+1.5 \mathrm{Air} \rightarrow \mathrm{CO}_{2}+2 \mathrm{H}_{2} \mathrm{O}+2 \mathrm{~N}_{2}----.- \text { eq. (1) } \\
& \mathrm{CH}_{3} \mathrm{OH}+1.5 \mathrm{Air}+3 \mathrm{CuSO}_{4} \rightarrow \mathrm{CO}_{2}+2 \mathrm{H}_{2} \mathrm{O}+2 \mathrm{~N}_{2}+ \\
& 3 \mathrm{Cu}+3 \mathrm{SO}_{4}
\end{aligned}
$$$$
\text { - eq. (2) }
$$$$
\mathrm{CH}_{3} \mathrm{OH}+1.5 \mathrm{Air}+3 \mathrm{NiCl}_{2} \rightarrow \mathrm{CO}_{2}+2 \mathrm{H}_{2} \mathrm{O}+2 \mathrm{~N}_{2}+
$$
$3 \mathrm{Ni}+3 \mathrm{Cl}_{2}$

$$
\begin{aligned}
& \mathrm{C}_{2} \mathrm{H}_{5} \mathrm{OH}+3 \mathrm{Air} \rightarrow 2 \mathrm{CO}_{2}+3 \mathrm{H}_{2} \mathrm{O}+2 \mathrm{~N}_{2} \text {----------- eq. (4) } \\
& \mathrm{C}_{2} \mathrm{H}_{5} \mathrm{OH}+3 \mathrm{Air}+5 \mathrm{NiCl}_{2} \rightarrow \mathrm{CO}_{2}+2 \mathrm{H}_{2} \mathrm{O}+2 \mathrm{~N}_{2}+5 \mathrm{Ni}+ \\
& 5 \mathrm{Cl}_{2}
\end{aligned}
$$

In this study for a given mixture fraction of reactants the flame temperature is calculated with and without salt and compared for the temperature variations. The flame temperature variation between the two cases of a pool flame is found to be within 5\%, which indeed helps to understand the variation in the thermo-physical parameters and also to check the variation in the chemical process due to addition of salt. It is assumed that this small change in temperature will not affect the physical parameters of the flame drastically.

The following tables $1.1,1.2$ and 1.3 shows the variation in the thermo-chemical reaction temperature (theoretical) with and without salts addition in moles which is calculated using chemical equilibrium and application software. Based on the flame temperature calculations, for Ethanol fuel 5 moles of Nickel Chloride is mixed and for Methanol fuel 3 moles of Nickel Chloride or Copper Sulfate is mixed.

Table 1.1: Ethanol Flame Temperature variation with and without Nickel Chloride

\begin{tabular}{|c|c|c|c|c|c|c|c|}
\hline \multicolumn{7}{|c|}{ Ethanol Air combustion with $\mathrm{NiCl}_{2}$} \\
\hline $\begin{array}{c}\text { Salt } \\
\text { amount } \\
\text { (moles) }\end{array}$ & $\begin{array}{c}\text { Without } \\
\text { salt }\end{array}$ & 0.05 & 0.1 & 0.5 & 1 & 3 & $\mathbf{5}$ \\
\hline $\begin{array}{c}\text { Temp. } \\
(\mathrm{K})\end{array}$ & 2199 & 2197 & 2196 & 2186 & 2173 & 2122 & $\mathbf{2 0 7 2}$ \\
\hline
\end{tabular}

Table 1.2: Methanol Flame Temperature variation with and without Nickel Chloride

\begin{tabular}{|c|c|c|c|c|c|c|c|}
\hline \multicolumn{7}{|c|}{ Methanol Air combustion with $\mathrm{NiCl}_{2}$} \\
\hline $\begin{array}{c}\text { Salt } \\
\text { amount } \\
\text { (moles) }\end{array}$ & $\begin{array}{c}\text { Without } \\
\text { salt }\end{array}$ & 0.05 & 0.1 & 0.5 & 1 & $\mathbf{3}$ & 5 \\
\hline $\begin{array}{c}\text { Temp. } \\
(\mathrm{K})\end{array}$ & 2147 & 2145 & 2143 & 2123 & 2099 & $\mathbf{2 0 0 6}$ & 1916 \\
\hline
\end{tabular}

Table 1.3: Methanol Flame Temperature variation with and without Copper Sulfate

\begin{tabular}{|c|c|c|c|c|c|c|c|}
\hline \multicolumn{7}{|c|}{ Methanol Air combustion with $\mathrm{CuSO}_{4}$} \\
\hline $\begin{array}{c}\text { Salt } \\
\text { amount }\end{array}$ & $\begin{array}{c}\text { Without } \\
\text { salt }\end{array}$ & 0.05 & 0.1 & 0.5 & 1 & $\mathbf{3}$ & 5 \\
\hline
\end{tabular}




\begin{tabular}{|c|c|c|c|c|c|c|c|}
\hline (moles) & & & & & & & \\
\hline $\begin{array}{c}\text { Temp. } \\
(\mathrm{K})\end{array}$ & 2147 & 2134 & 2113 & 2087 & 1983 & $\mathbf{1 9 2 6}$ & 1855 \\
\hline
\end{tabular}

As the pool size increased, the central part of the pool fire becomes more oxygen deprived, results into incomplete combustion and more smoke production for higher hydrocarbon fuels [5]. The pool flame setup of $0.05 \mathrm{~m}$ size is used for the experiment as shown in the Figure. 2. The preheating, transition and boiling processes were easily found from the fuel temperature variation of pool flame. The rate of fuel burning depends on the heat feedback from the flame to the fuel surface, and the mass burning rate controls the total heat release rate and the amount of heat feedback [7]. The variations in pool flame burning rate are understood by analyzing the rate fuel evaporation [4].

Shadowgraph technique consisting of concave mirrors, light source and a high speed camera is used to visualize the density gradient regions around the pool flame and could see the vortices shedding from the pool surface to the tip of flame. The dynamics of the flame vortex shedding near the intermittent zone and tip of the flame are captured and the flow field is analyzed to quantify the vortex shedding velocity. These vortices also explain the tip puffing phenomena and flame tip pinch-off effect. A high speed camera at 1000 frames per second is used to capture the details.

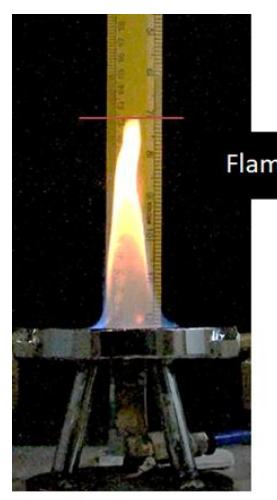

a. Ethanol

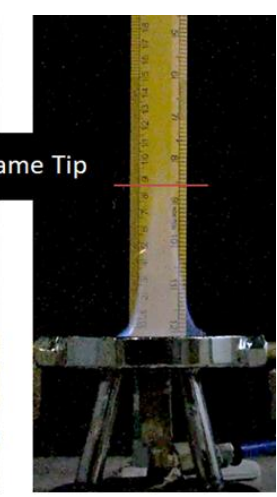

b. Methanol
Fig. 2. Pool Flame of $0.05 \mathrm{~m}$ diameter

As the pool flame is laminar in nature, and the flame is controlled by the buoyancy, only near the tip of the flame species acceleration is found due to flame pinch-off. The shedding vortices around the flame and the combusted species within the flame which is buoyancy controlled will have a constant velocity from the flame base till intermittent zone which further considered for validation of the new tracking methodology. To find change in momentum by the species in the flame, the dissociated fragments of salt which chemiluminescents are tracked using a high speed camera. The shadowgraph and chemiluminescents are captured simultaneously. Based on the vortex shedding velocity captured using shadowgraph, the species velocity measured using chemiluminescents are correlated. The diffusion of air into combustion zone due to concentration gradient and also buoyant force of evaporated fuel together decide the velocity of the species inside the combustion zone.

\section{RESULTS AND DISCUSSIONS}

The average burn rate is measured using a standard load cell having a sensitivity of $1 \times 10^{-7} \mathrm{~kg}$ and the burn rate is measured. The figure 2 shows variations in the burn rate for various time periods and found to be an average value of $2 \times 10^{-5}$ $\mathrm{kg} / \mathrm{s}$ and $1.8 \times 10^{-5} \mathrm{~kg} / \mathrm{s}$ respectively for methanol and ethanol pool flame. Figure 3 shows the pool flame height measured continuously including the flame tip puffing. The flame which is laminar in nature with small puffing at the flame tip is measured using a standard scale having a resolution of $0.001 \mathrm{~m}$ and measured flame height to be $0.0725 \mathrm{~m}$ for methanol pool flame and $0.118 \mathrm{~m}$ for ethanol pool flame from the pool surface.

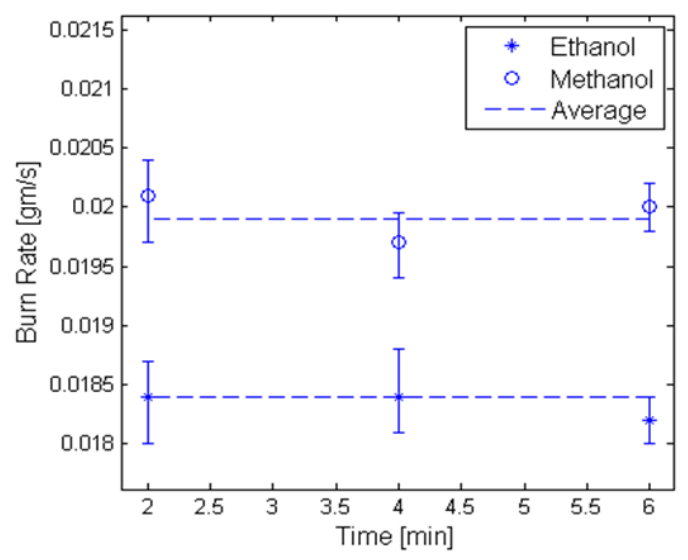

Fig. 2. Pool flame burn rate with time

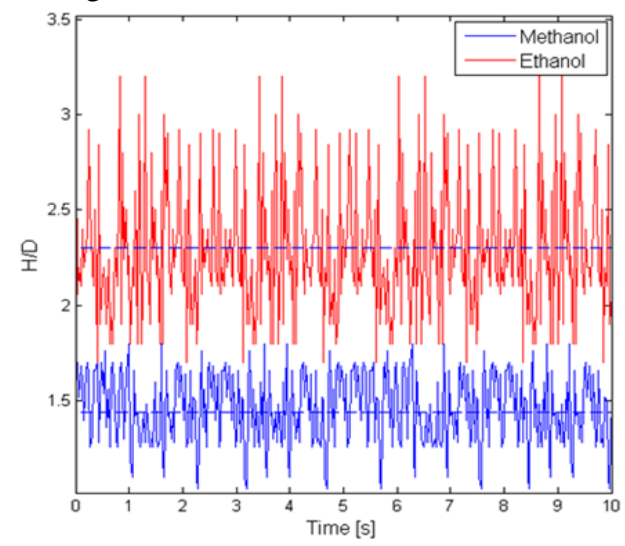

Fig. 3. Pool flame height variation with time

Figure 4 shows two shadowgraph images (at t1 \& t2) of Methanol and Ethanol flame each with an interval of 25 milliseconds. In these images, the indicated vortices are tracked using image processing technique and the appropriate 
velocity is calculated. The vortex shedding average velocity of the methanol pool flame is found to be $0.527 \mathrm{~m} / \mathrm{s}$ and the ethanol pool flame is $0.543 \mathrm{~m} / \mathrm{s}$.

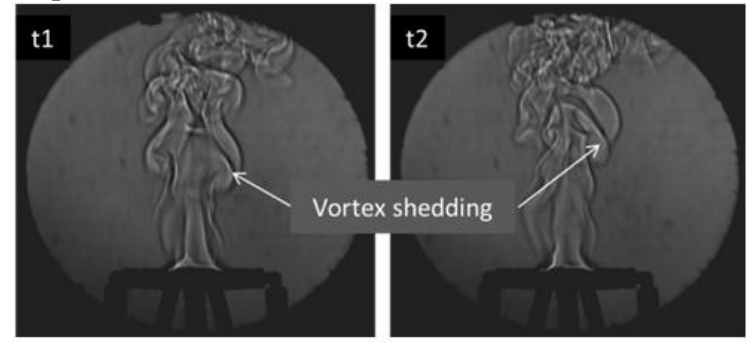

Ethanol|

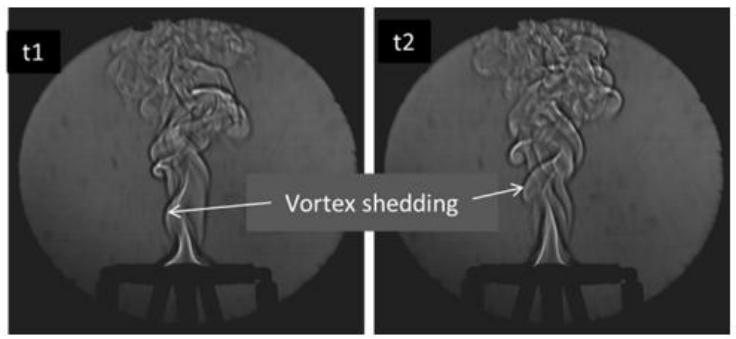

Methanol

Fig. 4. Shadowgraph of Pool Flame

The chemiluminescents images were captured at the same rate as of shadowgraph and a pixel calibration between 8 to 10 pixels per $\mathrm{mm}$ is used. Figure.5a. shows the chemiluminescents of ethanol pool flame with nickel chloride, similarly figure. 5.b and figure 5.c describes the chemiluminescents of methanol pool flame with copper sulfate and nickel chloride. The average velocity of methanol pool flame species in the flame zone (up to intermittent zone) is $0.525 \mathrm{~m} / \mathrm{s}$ with copper sulfate and $0.522 \mathrm{~m} / \mathrm{s}$ with nickel chloride and for ethanol pool flame with nickel chloride is $0.550 \mathrm{~m} / \mathrm{s}$.

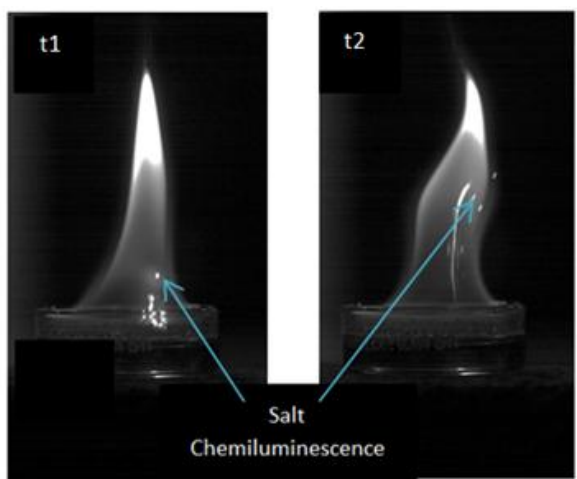

Ethanol Flame with Nickel Chloride a)

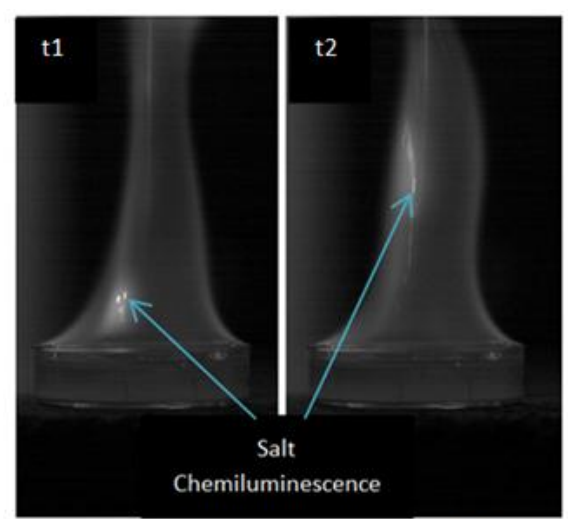

Methanol Flame with Copper Sulphate

b)

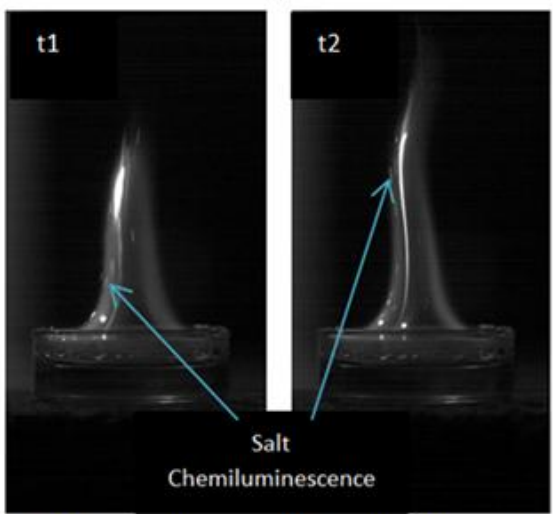

Methanol Flame with Nickel Chloride

c)

Fig. 5. Pool Flame with salt Chemiluminescence

The result of dynamics of pool flame chemiluminescence with salt in it provides species velocity to be very close as the vortex shedding velocity. A small deviation in the velocity is observed due to small density variation inside and around the flame. It is also observed that the dissociated salt will find variation in its velocity magnitude as it rises up from the tip of intermittent zone to flame tip due to pinch-off effect.

Table 2: Methanol and Ethanol Pool flame characteristics

\begin{tabular}{|c|c|c|}
\hline Characteristics & $\begin{array}{c}\text { Ethanol } \\
\text { Pool Flame }\end{array}$ & $\begin{array}{c}\text { Methanol } \\
\text { Pool Flame }\end{array}$ \\
\hline Burn Rate $(\mathrm{kg} / \mathrm{s})$ & $1.8 \times 10^{-5}$ & $2 \times 10^{-5}$ \\
\hline Average flame height $(\mathrm{m})$ & 0.118 & 0.0725 \\
\hline Vortex shedding velocity $(\mathrm{m} / \mathrm{s})[3]$ & 0.543 & 0.527 \\
\hline Chemiluminescence velocity $(\mathrm{m} / \mathrm{s})$ & 0.550 & $0.525 \& 0.522$ \\
\hline
\end{tabular}

The table 2 showcases the pool flame characteristics of Ethanol and Methanol using various methodologies. The burn rates are measured with a sensitivity of $1 \times 10^{-7} \mathrm{~kg} / \mathrm{s}$. The flame 
height, vortex shedding images and the chemiluminescence are captured with a pixel ratio of 10 pixels per $\mathrm{mm}$.

\section{IV.CONCLUSION}

In the research work, the burn rate of methanol and ethanol pool flame is $2 \times 10^{-5} \mathrm{~kg} / \mathrm{s}$ and $1.8 \times 10^{-5} \mathrm{~kg} / \mathrm{s}$, and average flame height of methanol and ethanol pool flame of pool size $0.05 \mathrm{~m}$ is $0.0725 \mathrm{~m}$ and $0.118 \mathrm{~m}$. The vortex shedding velocity around flame and the dissociated salt velocity using chemiluminescence photography are found to have similar magnitudes. The simple chemiluminescence technique can be utilized in finding the flow field in the diffusion flame without seeding particles externally. Based on the burn rate and the volume of fuel used, salts are added in the fuel at a mole ratio of 3 and 5 for methanol and ethanol fuel. The results of Chemical Equilibrium and Application helps in correlating the temperatures of flame with salts dissociated in the fuel.

Acknowledgment: Authors are very grateful to KLS GIT Belgaum for the support.

\section{REFERENCE}

1. Hamins, A., Kashiwagi, T., and Buch, R., 1995, Characteristics of pool fire burning, Fire resistance of Industrial Fluids.

2. Truchot, B., Durussel, T., and Duplantier, S., 2010, Combustion rate of medium scale pool fire, an unsteady parameter. International symposium on Safety Science and Technology, p. 575-585.

3. Mayur, A., Muruganandam, T., M., Raghavan, V., 2017, Dynamics of burning of laminar pool flame, $11^{\text {th }}$ AsiaPacific conference on combustion, Australia.

4. Hayasaka. H, 1997, Unsteady burning rates of small pool fires, $5^{\text {th }}$ symposium of Fire Safety Science, p. 499-510.

5. Sjostorm. J., Appel. G., Amon. F., 2015, Experimental results of large ethanol fuel pool fires, ETANKFIRE, Fire research.

6. Thomas. S., Stephen. W., Richard. C., Jose. L. T., 2007, Large scale pool fires, Thermal Science, p. 101-118.

7. Hamins, A., Kashiwagi, T., Fischer. S. J., 1994, Heat Feedback to the fuel surface in pool fires, Combustion science and Technology, vol. 97, p. 37-62.

8. Zhou. X. C., Gore. J. P., 1996, Measurement and prediction of air entrainment rates of pool fires, Twenty sixth symposium on combustion, p. 1453-1459. 